\title{
TECNOLOGIAS DIGITAIS: práticas e reflexões no contexto do ensino fundamental ${ }^{1}$
}

\author{
Eliana Maria do Sacramento Soares*
}

Carla Beatris Valentini $^{* *}$

\section{Resumo}

Estamos imersos no contexto digital. O que antes demorava para ser anunciado, hoje é feito instantaneamente em diferentes linguagens, o que muda a forma de ser e de estar dos sujeitos no mundo. Suas condutas são modificadas e, com elas, as formas de conhecer. Nesse contexto os processos educativos carecem de redimensionamentos a fim de inserir as escolas na cultura digital. Nesse artigo apresentamos um recorte de um estudo realizado no contexto do projeto UCA. Alguns conceitos da Biologia do Conhecer foram tomados como base teórica e a Pesquisa-Ação como abordagem metodológica, pois a pesquisa organizou-se a partir de uma experiência real em uma escola pública no contexto da inserção de laptops no modelo 1:1. Os dados foram construídos com base nos diários de bordo de pesquisadores que acompanharam essa experiência. Os registros foram analisados a partir da análise textual discursiva. Os resultados indicam que a inserção do laptop provocou a reconfiguração da sala de aula, em algumas situações, e a emergência de novas configurações de relações interpessoais entre estudantes e professores. Indicam ainda que o processo pedagógico está saindo, em alguns momentos, do foco do discurso do professor, abrindo novas possibilidades de interação em rede, onde estudantes e professores participam mais ativamente do processo educativo, atuando em convivência. Outro aspecto que foi encontrado é o tensionamento entre os domínios de ação do professor, que tem dificuldade de sair de seu papel de controle, e dos estudantes, que estão se constituindo em movimentos de exploração, questionamentos e interação.

Palavras-chave: Tecnologias digitais. Laptop. Biologia do conhecer. Ensino fundamental.

\section{DIGITAL TECHNOLOGIES: practices and reflections in the context of elementary school}

\section{Abstract}

We are immersed in digital context. What used to take longer to be announced is instantly announced in different languages nowadays, which changed the way people are and live in the world. Their behavior change and, as a consequence, their ways of knowing also change. In this context educational processes need to be reformulated in order to integrate digital culture into schools. In this paper we present an excerpt from a study conducted by the UCA project. Some concepts of Biology of Cognition were taken as theoretical basis and Action-research as the methodological approach, since the research was organized from a real experience for the implementation of

\footnotetext{
${ }^{1}$ Artigo vinculado ao projeto "Pesquisa e avaliação de práticas inovadoras para a inclusão da escola na cultura digital” com financiamento do Conselho Nacional de Desenvolvimento Científico e Tecnológico (CNPq).

Doutora em Metodologia do Ensino Superior pela Universidade Federal de São Carlos. Professora da Universidade de Caxias do Sul. E-mail: emsoares@ucs.br

** Doutora em Informática na Educação pela Universidade Federal do Rio Grande do Sul. Professora da Universidade de Caxias do Sul: E-mail: cbvalent@ucs.br
} 
a 1:1 laptop program in a public school. The data collection was based on information from log books of researchers who participated in the experiment. The records were analyzed through discourse analysis. The results showed that the implementation of the laptop program caused classroom reconfiguration and, in some situations, it promoted new interpersonal relationship configurations between teachers and students. The results also indicate that the educational process focused only on teacher's speech is losing field and opening up new possibilities for interaction in social networks, where students and teachers participate more in the educational process, working together. Another aspect observed was the teacher's dilemma as it is difficult for them to abandon their position of control and the students who are exploring, questioning and interacting.

Keywords: Digital technologies. Laptop. Biology of cognition. Basic Education.

\section{Contexto da cultura digital e espaços de aprendizagem}

Nossa sociedade está vivendo imersa no contexto digital, onde todas as áreas estão sendo influenciadas pela presença das tecnologias digitais, que mudam as formas de comunicação e de expressão. O que antes demorava para ser anunciado, hoje é feito instantaneamente, em diferentes linguagens. Isso muda a forma de ser e de estar dos sujeitos, ou seja, as condutas são modificadas e, com elas, as formas de conhecer.

Em todos os setores da sociedade vemos uma generalização das redes de computadores, que transformam especialmente as formas de comunicação interpessoais, tornando os fluxos de informação e de novidades praticamente instantâneas. Isso implica em mudanças em todas as áreas e a necessidade de constante adaptação. No caso da Educação, isso pode propiciar inovações relevantes no planejamento da prática educativa, em especial no diálogo pedagógico, que por sua vez pode se refletir na concepção da aprendizagem e do papel do professor. Nesse caso, o professor poderia redimensionar sua prática, criando ambientes de aprendizagem que possibilitem aos estudantes e a si mesmo interagirem e trabalharem juntos em problemas e projetos significativos. Isso pode contribuir para o desenvolvimento de habilidades necessárias para a formação de sujeitos capazes de relacionar-se com o contexto social contemporâneo, produzindo resultados significativos para o bem-estar social.

A escola inserida na sociedade não deveria refletir o que emerge nessa em termos de cultura digital? De que forma a sala de aula está se deixando provocar pela cultura digital?

Partimos do pressuposto de que a sala de aula é um espaço que deveria reverberar o contexto vivenciado pelos estudantes em seu cotidiano. Sob essa abordagem, a sala de aula, bem com a escola, estariam constantemente sendo desafiadas pelas demandas da sociedade na qual se inserem. Se essa está vivendo a cultura digital, parece então que a sala de aula e a escola deveriam estar sendo perturbadas pelas tecnologias digitais, que hoje mais do que 
nunca permeiam nosso cotidiano. Assim é fundamental pensarmos em como a incorporação das tecnologias digitais pode acontecer de forma a incrementar as práticas educativas. Incrementar, não apenas como simples ferramentas ou recursos para serem utilizados em determinados momentos isolados do processo educativo, ou para estudar conteúdos específicos, mas principalmente como elemento catalisador das mudanças das práticas docentes e cultura escolar vigente.

Como em geral se dá a comunicação pedagógica que é sustentada pela linguagem? Na maioria das vezes, pode acontecer pelo discurso do professor, que transmite informações, que podem ou não ser transformadas em aprendizagem, dependendo da ação e significação dos estudantes. Nessa perspectiva o layout da sala é organizado em fileiras, onde todos os estudantes enxergam o professor, mas não se enxergam, de forma que o estudante precisa acompanhar a exposição do professor aceitando-a como verdade. Assim, o acesso ao objeto de conhecimento é realizado, através do professor. Nesse contexto, conversas paralelas (que poderiam ser entendidas como interação), indicam a falta de atenção no que a professora ou professor está ensinando. Isso é uma abordagem baseada numa concepção empirista, em que se acredita que o professor possui o conhecimento e esse é transmitido ao estudante (FAGUNDES; VALENTINI; SOARES, 2010).

Em uma outra perspectiva, podemos ter estudantes e professores dialogando em torno de um objeto de conhecimento, onde a comunicação pedagógica se dá num processo dialógico em que o professor chama o estudante para pensar, problematizando, dando dicas, e juntos constroem o diálogo pedagógico. Nesse domínio de ação, o professor convida o estudante para pensar, questionar-se, discutir, e nesse caso, o layout da sala precisa ser mudado para outros formatos que permitam que estudantes e professores possam estar fisicamente em outras configurações, de forma que se enxerguem e que um estudante enxergue o outro, e não somente o professor. Assim outros elementos podem ser catalisadores do processo de aprender, além do discurso do professor. A forma como o diálogo pedagógico ocorre e a configuração a partir da qual a sala se organiza revela a concepção de educação e de processos educativos a partir dos quais o professor toma suas decisões e desenvolve sua prática educativa.

Qual desses contextos pode ser mais adequado para servir de cenário considerando a inserção das tecnologias digitais, tais como laptops, smartphones e tablets? Bem, a configuração em fileiras que induz a uma postura passiva, com foco apenas na escuta do professor, parece que não mais atende às demandas da educação, pautadas pela necessidade de desenvolver pensamento criativo, autonomia e capacidade de aprender a aprender. A outra 
configuração, onde os estudantes se colocam em equipes e interagem, parece que atende ou incentiva uma postura de cooperação e de parceria nas reflexões.

Configuração essa mais adequada se considerarmos que a aprendizagem é construída num processo de interações recorrentes. Então podemos dizer que para que a inserção das tecnologias digitais aconteça numa perspectiva de transformação, essa inserção precisa provocar mudanças, dentre elas as configurações das nossas salas de aula, o que por sua vez poderá estar contribuindo para mudanças na cultura escolar. Essas mudanças precisam acontecer principalmente na forma como os estudantes e professores se relacionam, tanto entre si, como com o objeto de conhecimento, que nesse caso tem como elemento potencializador as tecnologias digitais e a capacidade dessas de ser meio de comunicação e de interação entre esses sujeitos. Embora não seja objeto desse artigo, é relevante destacar que essas mudanças, para acontecerem nas condutas e práticas educativas, carecem de rompimentos epistemológicos.

Seguindo nessa reflexão, destacamos que o diálogo pedagógico, em grande parte, se estabelece a partir do discurso falado do professor e do texto impresso do livro didático e de outros textos de apoio. Nesse caso podemos dizer que o suporte do diálogo pedagógico é a fala do professor e o texto impresso no papel. Com a inserção das tecnologias digitais, como isso se modifica? Como elas interferem no processo de ensino aprendizagem? Refletir sobre como isso acontece pode nos ajudar a compreender o papel das tecnologias digitais nas práticas escolares.

As tecnologias digitais podem ser utilizadas para configurar espaços de aprendizagem, permitindo o registro e a socialização de atividades de aprendizagem. Deste modo, apesar da distância física, espacial e mesmo temporal, podem acontecer diálogos e mediações que fomentem a co-construção, a coautoria e o registro dinâmico das interações ocorridas no referido espaço.

Quando olhamos para o domínio de ação da sociedade, onde impera o uso dos recursos digitais nas suas diversas manifestações, e depois olhamos para o domínio de ação das escolas, em especial suas salas de aula, onde impera o ouvir e o escutar do diálogo pedagógico, percebemos que estamos falando de domínios que não se comunicam. Essa falta de comunicação entre esses domínios poderia estar acarretando certo desrespeito com os sujeitos estudantes? Ou ainda, essa desconexão entre as formas de pensar e de ser dos estudantes e dos professores não poderia levar os estudantes a sentirem-se excluídos do processo educativo? Caso isso seja verdadeiro, essa exclusão pode deixá-los isolados e isso pode ser uma variável que interfere na construção de aprendizagem. 
Com vistas a melhor compreender/explicar a dinâmica que pode ser estabelecida em um espaço de aprendizagem, no contexto da inserção de laptops, propomos que seja pensada pela perspectiva da Biologia do Conhecer, conforme Maturana (1997, 1999). Esse autor considera que existe uma relação de coerência entre as ações dos sujeitos na construção de seu viver na linguagem, na dinâmica das conversações. Ele destaca que o domínio de ação de um ser é onde ele vive e interage pela linguagem, modificando-se e sofrendo mudanças. Nas interações recorrentes de seu domínio de ação com o domínio de ação de outros sujeitos, no fluir das conversações, é que pode ser constituída a convivência que constrói outros domínios de ação, em um processo recursivo continuado entre meio e unidade (sujeitos), onde ambos atuam como fontes de perturbações mútuas.

Se pensarmos no domínio de ação dos professores atuando nas salas de aula e no domínio de ação dos estudantes, que estão imersos numa cultura digital, podemos perceber que existem poucas interseções entre eles, ou ainda que eles não estão em comunicação. Sob essa hipótese, um desafio é o acoplamento desses domínios de ação, para que professores e estudantes possam conviver num fluir de ações, que possibilitem a aprendizagem.

\section{Aprendizagem a partir da Biologia do Conhecer}

Na perspectiva da Biologia do Conhecer, a aprendizagem é entendida como mudanças estruturais que decorrem de interações recorrentes. Nesse sentido, a aprendizagem é fruto de interações que perturbam o sujeito, de forma que mudanças ocorrem em sua estrutura interna. Desse ponto de vista, o que ocorre fora da estrutura do sujeito não determina a aprendizagem, mas sim a forma que ele as significa em sua estrutura. Sob essa abordagem os fluxos de interação podem constituir uma rede de comunicação que, por sua vez, pode potencializar a aprendizagem. Nesse caso, ela se manifesta em mudanças e transformações que ocorrem no contexto de vida dos estudantes e que podem ser observadas em suas condutas. Mudanças no fazer implicam em mudanças no ser, já que ambos estão acoplados (Maturana, 1999) e considerando que fazer e ser integram uma totalidade e estão implicados.

Diante dessas concepções, planejar um espaço de aprendizagem é configurar um espaço de convivência, de modo que os atores do processo de aprendizagem possam fluir juntos no conviver, numa história de interações recorrentes. Dito de outra forma, a tarefa do professor é conviver com o estudante, numa circunstância, transformando-o e transformandose em interações recorrentes, num mesmo domínio de ação. Um espaço de aprendizagem é um local que precisa propiciar essa convivência, a partir de um objetivo em comum: a 
discussão e reflexão sobre conteúdos teóricos específicos, com base em orientações e tarefas propostas em parceria por professor e estudantes. É um local de discussão suportado pelos fluxos de comunicação em torno dos temas em estudo, constituído, em geral, por comentários, perguntas, respostas, sistematizações. A forma como ele se organiza ou emerge dependerá das tarefas propostas e das orientações e intervenções apresentadas. Em uma visão de aprendizagem como construção, fruto da convivência sócio cognitiva, que se assume nesse contexto, é desejável que essas discussões se organizem em rede, no sentido de ultrapassar fluxos do tipo pergunta/resposta ou mensagem/resposta, em que o estudante pergunta e o professor responde, para serem fluxos de coordenação de coordenações de ações, movimentos recursivos.

A aprendizagem mediada por tecnologias de comunicação e de informação não é apenas uma questão técnica. Ela traz consigo mudanças que vão muito além de aspectos técnicos, pedagógicos e administrativos. Mudanças estas que estão relacionadas a uma nova forma de pensar. E, nesse sentido, é importante destacar que se o uso das tecnologias digitais não romper com o paradigma empirista de ensino-aprendizagem, estas serão apenas mais uma ferramenta para o repasse de informações, e não uma efetiva possibilidade de construção do saber por parte de estudantes e professores. Nesse caso, pode acontecer que apesar da inserção dessas tecnologias, movimentos inovadores possam não existir.

Como destaca Pellanda (2009), um ambiente de aprendizagem mediado por tecnologias digitais é de uma plasticidade incrível, que permite ao sujeito (estudante) ser desafiado a múltiplas ações, levando-o a possibilidades diversas de aprendizagem. Ele, por exemplo, pode ser incentivado a se aventurar por diversos caminhos que requerem atitudes de autonomia, onde o que ele não sabe dá lugar à busca. Essa plasticidade pode ser entendida a partir das ideias da Biologia do Conhecer, que tem suas bases na teoria dos fluxos da cibernética. Assim, o aprender está relacionado com o viver, entendido como fluxos circulares, recursivos e auto-organizadores.

\section{Percurso metodológico}

Tomamos a Pesquisa-Ação como o pano de fundo da abordagem metodológica, isso porque essa pesquisa organizou-se a partir de uma experiência real no contexto da escola pública a partir da inserção de laptops no modelo 1:1, onde cada estudante e professor possui seu equipamento. Esse artigo está relacionado a um projeto de pesquisa mais amplo, denominado "Pesquisa e avaliação de práticas inovadoras para a inclusão da escola na cultura 
digital”, uma parceria entre a Universidade Federal do Rio Grande do Sul, a Universidade de Caxias do Sul e a Universidade do Vale do Rio dos Sinos, sob a coordenação geral da professora Dra. Léa da Cruz Fagundes. Esse projeto conta com financiamento do Conselho Nacional de Desenvolvimento Científico e Tecnológico (CNPq) e inclui mestrandos, bolsistas de iniciação científica e professores das escolas públicas envolvidas na etapa II do Projeto “Um computador por Aluno (UCA)” do Governo Federal, e futuramente trará resultados mais aprofundados.

A pesquisa ação integral e sistêmica (PAIS) é uma metodologia de pesquisa que utiliza o pensamento sistêmico para buscar a compreensão de um fenômeno complexo ativo em um ambiente igualmente em evolução, no intuito de permitir a um ator coletivo intervir para induzir uma mudança (Morin, 2004).

Os dados se referem a uma escola de ensino fundamental da rede pública municipal, situada na Região Nordeste do Rio Grande do Sul, no Sul do Brasil. Essa escola atende crianças e jovens de classe média, provenientes dos bairros próximos, contando com cerca de 450 estudantes e 50 professores. Os estudantes utilizam com facilidade os recursos digitais na escola e também possuem acesso a esses recursos em seus lares. Alguns professores não eram familiarizados com o uso de computador e laptop antes do projeto, mas estão todos inseridos no processo de "Formação continuada de professores UCA-RS”, com encontros presenciais e mediado pelo ambiente virtual E-proinfo.

Os diários dos pesquisadores que compõem os dados de análise são registros das observações de aulas em que foi utilizado o laptop. Destacamos que ele é utilizado em todas as disciplinas, mas em momentos específicos definidos pelo professor e equipe pedagógica da escola. O diário serve para anotar o que acontece no campo de pesquisa e conta com as notas de observação do pesquisador, que abrangem todos os fatos pertinentes relativos ao problema, tudo o que se pode acrescentar ou recortar. O diário organiza-se também com as notas teóricas e práticas, que enriquecem a compreensão do problema em estudo. Para análise deste artigo foram consideradas observações de quatro situações de salas de aula de turmas de $6^{\circ}$ e $8^{\circ}$ anos.

Os dados foram construídos a partir dos diários de bordo de pesquisadores que acompanharam a escola e as turmas em seu movimento de inserção dos laptops na sala de aula. Os registros foram analisados a partir da análise textual discursiva de Moraes e Galiazzi (2007), com vistas à produção de compreensões de discursos da linguagem, em movimentos interpretativos de caráter hermenêutico. A análise textual oferece uma alternativa que ultrapassa a fragmentação e o reducionismo, marcantes em formas históricas da análise de 
conteúdo. Para tanto, o descrever e o explicar, a partir do corpus, é constituído por operações recursivas de ir e vir entre o corpus e a teoria. Isso foi realizado na busca de superar juízos de valor, entendendo as situações estudadas a partir das observações feitas visíveis através de enunciados registrados.

Este movimento analítico possibilitou a emergência de três categorias a) movimentos de configuração e layout da sala de aula; b) comunicação e interação em rede e reconfiguração de papéis e c) tensionamentos do conviver e saber entre professores e estudantes. Na primeira categoria discutiu-se como a inserção do laptop provocou a reconfiguração da sala de aula e a emergência de novas configurações de relações interpessoais entre estudantes e professores. Na segunda, o processo pedagógico em que a mudança do foco do discurso do professor se desloca e abre novas possibilidades de interação em rede, onde os estudantes participam mais ativamente do processo. Por fim, na terceira categoria discutem-se os tensionamentos entre os domínios de ação do professor, que tem dificuldade de sair de seu papel de controle, e dos estudantes, que estão se constituindo em movimentos de exploração, questionamentos e interação.

\section{Análise das observações}

\section{Movimentos de reorganização do layout da sala de aula}

Na constituição dessa categoria, dos quatro registros das situações de sala de aula observadas, três indicam movimentos de reorganização de seu layout. Nessas situações, no início da aula, a organização da sala é a tradicional, com mesas enfileiradas, um estudante atrás do outro e o professor iniciando a proposta da atividade. Com a presença do laptop a sala de aula se reorganiza, no decorrer do encontro. Essa reorganização, em nenhuma das situações, foi proposta ou antecipada pelo professor; esse movimento foi acontecendo na medida em que os estudantes recebiam os laptops, que estavam guardados em um armário ao fundo da sala. A entrega dos laptops era feita por um ou dois colegas responsáveis por essa tarefa. A reorganização da sala de aula se deu não só em relação à disposição das mesas e cadeiras, que se agruparam em duplas ou trios, mas também em relação às interações entre os estudantes, que aconteceram de forma mais espontânea e compartilhada.

Em uma das situações encontramos dois professores na sala de aula, orientando os estudantes, evidenciando modificação no espaço de aprendizagem, pois em geral temos um professor responsável por cada disciplina atuando em sala de aula. Essa modificação está no 
fato de que os professores atuam individualmente em cada disciplina; quando atuam em equipe, como nesse caso parece estar ocorrendo, estamos percebendo movimentos de ação coletiva, que podem ou não se desdobrar em interações entre os professores na busca de inovações em suas práticas pedagógicas.

Não podemos afirmar que houve mudanças nas concepções de aprendizagem dos professores, mas o simples fato de eles terem permitido a reorganização dos estudantes em grupos de estudo para realização das tarefas revela alguma modificação em suas práticas. Embora tenha sido natural essa reorganização para trabalhos em grupo, em alguns casos observamos que o professor não permitiu isso, pois talvez entenda essa reorganização como prejudicial a aprendizagem, uma vez que o estudante desloca a sua atenção da tarefa proposta para as trocas entre os colegas. Essa conduta do professor pode revelar uma concepção de aprendizagem baseada no controle: estudantes interagindo fogem do controle do professor e do cumprimento de seu planejamento pedagógico. Parece ainda que essa conduta pode indicar uma concepção de aprendizagem baseada na realização de tarefas propostas, desconsiderando exploração, cooperação e problematização.

Em algumas situações encontramos a manutenção da organização tradicional da sala de aula, onde os estudantes estão perfilados um atrás do outro, caracterizando um layout relacionado a um processo de ensino diretivo e tradicional. Nesse caso, o professor determina que os estudantes não possam movimentar-se e conversar com os colegas, devido à "falta de bom comportamento" dos estudantes nas aulas anteriores. Isso revela uma atitude controladora e de ameaça por parte do professor. Nesse contexto o que rege a dinâmica de aprendizagem é sua concepção empirista, segundo a qual para aprender, os estudantes precisam realizar a atividade em silêncio, sem interagir e prestando atenção nas orientações e discurso do professor. Além disso, podemos inferir que nesse caso a presença do laptop não foi perturbadora, no sentido de levar a uma desestabilização das dinâmicas vigentes.

Os trechos do diário de observação, destacados a seguir, ilustram as propostas pedagógicas em que o laptop é utilizado:

As atividades propostas em aula eram inicialmente a construção de slides sobre um poema criado em aulas anteriores e adicionar imagens aos slides. Inicialmente os estudantes deveriam transpor o conteúdo de seus cadernos para os slides e em um segundo momento procurar imagens, ou no pendrive da professora ou na internet, que fossem de acordo com seus poemas. Se sobrasse tempo os estudantes eram convidados a colocar animações em seus slides. Por fim, quem acabasse deveria navegar na internet no site indicado pelo professor. ( $6^{\circ}$ ano - Disciplina $\mathrm{X}$ ). 
A análise dessas observações permite inferir que a presença da tecnologia digital, por si só, não promoveu transformações nos espaços educativos e tampouco aproximou a escola da cultura digital, pois muitas atividades não evidenciaram mudanças metodológicas.

\section{Comunicação e interação em rede e reconfiguração de papéis}

Nas situações observadas, para a constituição dessa categoria, consideramos movimentos de comunicação e interação entre professores e estudantes, bem como o fato de esses movimentos evidenciarem a manutenção ou a transformação da prática docente tradicional empirista e da posição do estudante como receptor passivo de informações. A partir da análise do corpus encontramos intensificação da interação entre os estudantes, motivadas pelas tarefas solicitadas pelas professoras e por questões ou problemas relacionados à apropriação da tecnologia. Na maioria das situações observadas o professor deixou de estar na posição de transmissão de informação. Na estrutura de aulas expositivas, suas ações apareceram relacionadas às orientações aos estudantes em pequenos grupos ou individualmente.

Os trechos do diário de observação, destacados a seguir, ilustram essas considerações:

Na maior parte do tempo os professores auxiliavam os estudantes, ou em pequenos grupos, além de solicitar que os estudantes auxiliassem seus colegas. Ambos os professores passaram os dois períodos de aula em constante movimento, corrigindo, auxiliando e gerenciando a turma. $\left(6^{\circ}\right.$ ano - Disciplina X)

Durante a aula, um estudante, com o professor ao seu lado conseguiu inserir imagens no seu mapa conceitual. Após um período de tempo o professor, ao ser indagado sobre este mesmo processo, afirmou: "eu não sei, quem conseguiu foi o fulano”. ( $6^{\circ}$ ano - Disciplina Y)

Conforme os estudantes procuravam sobre o assunto e anotavam, eles comunicavam uns aos outros as fontes encontradas. ( $8^{\text {a }}$ série - Disciplina Z)

Nas situações observadas relacionadas a essa categoria, encontramos intensificação da interação entre os estudantes, motivada pelas tarefas solicitadas pelos professores e por questões ou problemas relacionados à apropriação da tecnologia digital como mediadora do processo educativo. Na perspectiva da Biologia do Conhecer, a aprendizagem é entendida como mudanças estruturais que decorrem de interações recorrentes. Ou seja, os fluxos de interação constituem a rede de comunicação, a qual pode potencializar a aprendizagem, manifesta em mudanças e transformações que ocorrem no contexto de atuação dos estudantes e professores. Sob essa abordagem teórica, podemos entender estudantes e professores, 
quando organizados nessa configuração de interações recorrentes, convivendo em um historial de modificações estruturais sob interações recorrentes com sua circunstância, no caso, a inserção do laptop no cenário educativo.

Outro aspecto que se evidenciou é a posição ativa dos estudantes, assumindo opiniões, buscando alternativas e soluções, compartilhando descobertas e ajudando os demais colegas e professor. Podemos dizer que as questões de apropriação tecnológica são as que mais provocam esse movimento de posição ativa dos estudantes, pois eles evidenciam um desejo de compartilhar e mostrar aos colegas e professor o que estão produzindo e os novos caminhos que estavam encontrando. Esse movimento nasceu, em todos os casos observados, sem a orientação específica do professor para ações de compartilhar e de colaborar.

Um dos princípios da cultura digital destacados por Lemos (2009, p. 39) refere-se à possibilidade de emitir em rede, conectar-se com outras pessoas, "produzir sinergias, trocar pedaços de informação, circular, distribuir”. As ações dos estudantes indicaram um movimento natural em direção a essa socialização e distribuição das informações, embora ainda os professores estejam dando pouca abertura e propiciando poucos espaços para que essas trocas e publicações aconteçam na web. As publicações na web, quando realizadas, são feitas pelos professores a partir dos materiais e produções dos estudantes.

A inserção do laptop na sala de aula parece tê-la transformado em um espaço de convivência: a aula apenas expositiva começa a ceder lugar a interações recorrentes; a posição centralizadora do professor começa a se modificar para uma atitude aberta a trocas não hierárquicas. Essas trocas heterárquicas se manifestaram nos desafios provocados pela apropriação da tecnologia e no uso dos softwares, ou seja, estudantes e professores se apropriando desses novos recursos conjuntamente.

Embora a análise das observações indique que há uma movimentação dos espaços comunicativos e das práticas pedagógicas, esse movimento ainda é inicial e pode ou não constituir inovações nos processos de ensinar e aprender. Para a escola se inserir na cultura digital é necessário abrir possibilidades para construção de novas práticas e novos papéis tanto para os professores como para os estudantes de uma forma mais consistente.

\section{Tensionamentos do conviver e saber entre estudantes e professores}

Nessa categoria evidenciam-se os diferentes domínios de ação de professores e estudantes: os primeiros são sustentados pela sua formação e pela necessidade que defendem de atender a um currículo previamente definido; os segundos se desenvolvem no contexto da 
cultura digital, com inquietações e pouco interessados nos conteúdos pré-estabelecidos pelas escolas. Podemos perceber que há poucas interseções entre eles, ou ainda, que eles não estão em comunicação. Esses diferentes domínios de ação provocam tensionamentos entre os sujeitos do processo de ensino e aprendizagem. Poderiam os usos das tecnologias digitais movimentar uma aproximação entre esses dois domínios facilitando um conviver no fluir de ações? O que se faz necessário para que se construa esse caminho?

Nos diários temos que:

A atividade proposta pelo professor consistia em pesquisar na internet, encontrar imagens e salvar em uma pasta apropriada e fazer anotações no caderno sobre o assunto. ( $8^{\mathrm{a}}$ série - Disciplina Z)

O professor permaneceu sentado em sua classe na maior parte da aula, pesquisando sobre o assunto proposto no laptop, indicando vídeos e sites verbalmente. ( $8^{\mathrm{a}}$ série - Disciplina $\mathrm{Z}$ )

O professor explicou que, de forma geral, mapas conceituais consistiam em palavras-chaves ligadas a outros conceitos através de verbos ou frases. Após a explicação foi solicitado que os estudantes produzissem um Mapa Conceitual conforme o modelo do livro para "treinamento". O professor X acompanhou toda a aula. Após seria proposto a realização de um Mapa Conceitual do conteúdo explicado pelo professor (que será realizado na próxima aula). (8 $8^{\text {a }}$ série - Disciplina Z)

Em muitas atividades encontramos o professor apresentando passos bem definidos para a tarefa, sem contemplar os conhecimentos prévios dos estudantes sobre os softwares que estavam sendo utilizados e seu nível de letramento digital.

O conceito de letramento digital diz respeito à utilização das tecnologias digitais para uma prática crítica e consciente, a fim de dar sentido a essa utilização, de forma que seja relevante na sua atuação enquanto sujeito agindo e sendo no mundo. Sob essa abordagem, esse conceito inclui o uso das tecnologias digitais como uma competência específica, de forma significativa, entendendo seus limites e suas potencialidades no contexto de sua prática social e educativa. Isso quer dizer que esse uso precisa acontecer de forma a dar sentido a essa prática no seu domínio de ação.

Nessa categoria, os registros mostram que ainda é comum os professores solicitarem que os estudantes façam a estrutura prévia do mapa conceitual ou o texto no papel para depois trabalhar no laptop. Também encontramos momentos em que as buscas de informações na web realizadas pelos estudantes no laptop são transcritas para o caderno, o que parece contraditório, já que cada estudante possui o seu laptop. 


\section{Considerações finais}

Os resultados desse estudo indicam que o cenário da inserção de laptop na sala de aula pode ser entendido como um domínio de ação onde professores e estudantes estão convivendo a partir de um objetivo em comum: a exploração e apropriação do laptop como recurso pedagógico. Em alguns casos, esse domínio se constitui numa circunstância de interações recorrentes, que apresentam novas configurações e, em outros, circunstâncias de conflito ou de desencontro, onde ainda não ocorrem interações recorrentes, apenas esporádicas.

Acontecem transformações estruturais e de convivência quando existe a exploração compartilhada e com respeito mútuo, suportada pelos fluxos de comunicação em torno dos temas de interesse. Onde existe negação e resistência, as transformações e a convivência não acontecem.

A forma como esses domínios se organizam ou emergem dependerá das condutas de professores e estudantes existindo juntos em coordenações de ações e movimentos recursivos: interações recorrentes. Dito de outro modo, as trocas comunicativas do e no domínio se constituem em redes de conversações, baseadas em um ir e vir dialógico, que pode ser o reflexo de uma convivência e que pode promover as mudanças estruturais que, por sua vez, podem resultar em mudanças de conduta, revelando a aprendizagem (RECH e SOARES, 2009).

Percebemos na maioria das observações, por conta da gestão pedagógica, o processo ainda centrado no professor, que é o foco do cenário, no sentido de dar ordens, propor as tarefas, centralizar e definir quando o laptop pode ser utilizado. Mesmo assim, podemos perceber movimentos iniciais de autonomia dos estudantes, ao problematizar e chamar o colega para reflexões, para mostrar descobertas e convidar à exploração conjunta, sem depender do professor. Todavia, estas ainda são situações de exceção, pois, no caso do corpus estudado, a análise mostra que muitas vezes a ação é desenvolvida em um domínio de dependência, ou seja, do ainda continuar a agir de determinada forma. O que se pode constatar é que numa dimensão intelectiva entende-se a necessidade da mudança, mas na ação ainda não se sabe como agir. Maturana e Verdezn-Zöller (2004) afirmam que é a convivência das emoções aprendidas que leva à conservação do que fazemos e sabemos. Talvez seja por isso que tanto os estudantes quanto os professores revelem em suas ações no decorrer do processo o que sabem e o que aprenderam na cultura na qual convivem ou conviveram e que, na maior parte dois casos, ainda é uma cultura de passividade e de dependência. 
Dessa forma, no que se refere à convivência, o resultado da análise parece evidenciar que a gestão do ambiente não foi adequada para possibilitar a emergência de fluxos de interações recorrentes com uma organização que caracterizasse a convivência.

Com vistas a contribuir com o avanço de propostas inovadoras no cenário da inserção de laptop e de outras tecnologias digitais, é fundamental aprofundar o questionamento a respeito das estratégias e dinâmicas utilizadas nesse contexto. Pode, então, ser útil perguntar e refletir sobre: O que precisa ser ressignificado, tanto por parte do estudante (esse talvez tenha familiaridade com a presença do laptop) como do professor, para que os fluxos de comunicação ultrapassem a linearidade e se organizem em redes? O que se requer para que se constitua uma comunidade que convive, de modo que essa convivência resulte em transformações estruturais, em aprendizagens significativas e na construção de conhecimento no contexto da inserção das tecnologias digitais?

Maraschin e Axt (2005, p. 9), em uma pesquisa que se inscreve no campo de interlocução entre as Ciências Cognitivas e as tecnologias digitais, destacam que "um ambiente de aprendizagem suportado por um sistema telemático de comunicação institui uma nova relação com o conhecimento, implicando o contato com um terceiro na relação professor-aluno, que é o próprio recurso possibilitador da interação". De forma semelhante, Bisol (2005) aponta para apropriação do conhecimento quando os meios digitais levam o estudante a ocupar um novo lugar diante do outro, um espaço que rompe com as fronteiras convencionais de tempo, espaço e senso-percepção.

Podemos inferir que o uso das tecnologias digitais, na perspectiva destacada pelas autoras mencionadas no parágrafo anterior, poderá acontecer como resultado da convivência, que por sua vez precisa ser suportado pelos fluxos de interação recorrentes entre professores e estudantes. A forma como esse fluxo se organiza está diretamente relacionado às condutas e ações recursivas entre esses atores do processo educativo, além dos gestores. Essa organização requer mudanças em seu padrão advindas de mudanças epistemológicas na forma de entender o processo educativo, de compreender o estudante e o professor como sujeitos sistêmicos, de maneira que suas ações precisam ser entendidas desde essa perspectiva e dessa abordagem; requer pensar nas formas de auxiliar a redimensionar e repensá-las, no caso de nossos estudos, no contexto da cultura digital. 


\section{Referências}

BISOL, C. A. Ciberespaço: terceiro elemento na relação ensinante-aprendente. In: VALENTINI, C. B. \& SOARES, E. M. S. (Org.) Aprendizagem em Ambientes virtuais: compartilhando ideias e construindo cenários. Caxias do Sul: Educs, 2005.

FAGUNDES, L. C.: VALENTINI, C. B.; SOARES, E. M. S; Linguagem, educação e recursos midiáticos: quem mexeu na minha escola? In: Ética, Educação e Tecnologia: pensamento em alternativas para os desafios da educação na atualidade. Pescador, C. Soares, E. M. S., Nodari, P. C. (Org.). Curitiba: Editora CRV, 2010.

LEMOS, A. 2009. Cibercultura como território recombinante. In: TRIVINHO, E., CAZELOTO, E. (eds.). A cibercultura e seu espelho: campo de conhecimento emergente e nova vivência humana na era da imersão interativa. São Paulo: ABCiber, Instituto Itaú Cultural, pp. 38-46. Disponível em:

$<$ http://abciber.org/publicacoes/livro1/a_cibercultura_e_seu_espelho.pdf $>$. Acesso em: 22 abr. 2012.

MARASCHIN, C. e AXT, M.. Acoplamento Tecnológico e Cognição. In: VIGNERON, J. e OLIVEIRA, V. B. (Org). Sala de aula e tecnologias. São Bernardo do Campo: Universidade Metodista de São Paulo, 2005. pp. 39-51.

MATURANA, H. A ontologia da realidade. Humberto Maturana; Cristina Magro; Miriam Graciano e Nelson Vaz (org.). Belo Horizonte: Ed. UFMG, 1997.

MATURANA, H. Emoções e linguagem na educação e na política. Belo Horizonte: Ed. UFMG, 1999.

MATURANA, H; VERDEZN-ZÖLLER, G.. Amar e brincar: fundamentos esquecidos do humano. São Paulo: Palas Athena, 2004.

MORAES, R. ; GALIAZZI, M. C. Análise textual discursiva. Ijuí: Ed. Unijuí, 2007.

MORIN, A. Pesquisa-ação integral-sistêmica: uma antropologia renovada. Rio de Janeiro: DP\&A, 2004.

PELLANDA, N. M. C. Maturana \& a Educação. Belo horizonte: Autentica. 2009.

SOARES, E. M. S.; RECH, J. Refletindo sobre processos educativos em ambientes virtuais à luz da Biologia do Conhecer. In: Revista Informática na Educação: teoria \& prática, v. 12, n.2/2009. 